\title{
A synchrotron XAS study of molybdenum speciation in sulfur- bearing hydrothermal fluids
}

\author{
WEIHUA LIU ${ }^{1}$, BARBARA ETSCHMANN ${ }^{2}$, YUAN MEI ${ }^{1}$, \\ DENIS TESTEMALE ${ }^{3}$, QIUSHI GUAN ${ }^{1,2}$ AND JOËL \\ BRUGGER $^{2}$ \\ ${ }^{1} \mathrm{CSIRO}$ \\ ${ }^{2}$ Monash University \\ ${ }^{3}$ Institut Néel - CNRS \\ Presenting Author: weihua.liu@csiro.au
}

Knowledge of the identity and thermodynamic properties of aqueous molybdenum (Mo) species at elevated temperatures and pressures is important for understanding the extraction of Mo from source rocks and the formation of hydrothermal deposits. Chlorine and sulfur are two major components in crustal fluids. Several studies have investigated Mo speciation and solubility in chloride-bearing hydrothermal fluids, but little is known about the behaviour of Mo in sulfur-bearing systems. We used in-situ synchrotron X-ray absorption spectroscopy (XAS) measurements and molecular dynamics (MD) simulations to investigate the predominant Mo species in S-bearing (0.04-2 $\mathrm{m}$ NaHS) solutions at $30-394{ }^{\circ} \mathrm{C}(\mathrm{XAS})$ and $77-300{ }^{\circ} \mathrm{C}$ (MD) and 800bar. The XAS data show that, similar to previous room temperature studies, the $\mathrm{S}^{2-}$ ion progressively replaces $\mathrm{O}^{2-}$ in molybdate $\left(\mathrm{MoO}_{4}{ }^{2-}\right)$ to form thiomolybdates $\left(\mathrm{MoO}_{4-\mathrm{x}} \mathrm{S}_{\mathrm{x}}{ }^{2-}, \mathrm{x}=1,2,3,4\right)$ with increasing NaHS concentrations at temperature up to $394{ }^{\circ} \mathrm{C}$. The MD simulations confirm the identity and structure of the thiomolybdate species determined from the XAS experimental data. The speciation calculations based on the formation constants for the thiomolybdate species extrapolated from the room temperature data agree well with the experimental results. This study indicates that thiomolybdate species are likely to be important in transporting Mo in sulfur-bearing, wide $\mathrm{pH}$ ranges (e.g., $\mathrm{pH}$ 5-9 at $300{ }^{\circ} \mathrm{C}$ ) hydrothermal fluids under reduced (sulfide stable) conditions in the Earth crust. Current models of Mo transport in hydrothermal ore fluids need to be re-evaluated to take into account the thiomolybdate species.

\section{Reference:}

Liu, W., Etschmann, B., Mei, Y., Guan, Q., Testemale, D. and Brugger, J. (2020) The role of sulfur in molybdenum transport in hydrothermal fluids: Insight from in situ synchrotron XAS experiments and molecular dynamics simulations. Geochimica et Cosmochimica Acta 290, 162-179. 